\title{
Role of IL-9 and STATs in hematological malignancies (Review)
}

\author{
$\mathrm{NACHEN}^{1}$ and XIN WANG ${ }^{1,2}$ \\ ${ }^{1}$ Department of Hematology, Provincial Hospital Affiliated to Shandong University, Jinan, Shandong 250021; \\ ${ }^{2}$ Department of Diagnostics, Shandong University School of Medicine, Jinan, Shandong 250012, P.R. China
}

Received June 6, 2013; Accepted December 9, 2013

DOI: 10.3892/ol.2013.1761

\begin{abstract}
Although interleukin-9 (IL-9) exhibits pleiotropic functions in the immune system, it remains a well-known cytokine in hematological malignancies. Previous cell culture and animal model studies have revealed that the Janus kinase-signal transducer and activator of transcription signaling pathway, which may be activated by a number of cytokines including IL-9, is critical in hematological malignancies. The current review summarizes the characterization of the biological activities of IL-9, highlights the clearly defined roles of the cytokine, and outlines questions with regard to the functions of IL-9 that require further exploration and their downstream signaling proteins, signal transducers and activators of transcription.
\end{abstract}

\section{Contents}

1. Introduction

2. IL-9 production and function

3. Characteristics and expression of STATs

4. Role of STAT3 and STAT6 in IL-9 production and immune function

5. Conclusions and future directions

\section{Introduction}

Interleukin (IL)-9 is a member of the common $\gamma$-chain family of cytokines, using the $\gamma$-chain receptor in combination with the cytokine-specific receptor, IL-9 receptor (IL-9R) $\alpha$ (1). There has been renewed interest in IL- 9 since the identification of a subset of $\mathrm{T}$ cells which produce this cytokine. However, previous conflicting studies have been identified, concerning which $\mathrm{T}$ cells produce this cytokine. The studies demonstrated, but are not limited to, the following $\mathrm{T}$ cells: $\mathrm{T}$ helper

Correspondence to: Professor Xin Wang, Department of Hematology, Provincial Hospital Affiliated to Shandong University, 324 Jingwu Road, Jinan, Shandong 250021, P.R. China

E-mail:xinw@sdu.edu.cn

Key words: hematological malignancies, IL-9, STAT3, STAT6
(Th) 2,9 and 17 cells and regulatory T (Treg) cells. Besides the role of IL-9 during immune responses, its growth factor and antiapoptotic activities on multiple transformed cells suggest a potential role in hematological malignancies. Notably, IL-9 overexpression induces thymic lymphomas in mice, and IL-9 production has an effect on Hodgkin's disease and human T-lymphotropic virus type I (HTLV-I)-transformed T cells in humans. IL-9 activities also involve IL-2, -4, -7, -15 and -21 signaling, which is mediated by a specific receptor chain that forms a heterodimeric receptor with the common $\gamma$ chain (2). The IL-9R and common $\gamma$ chains associate with Janus kinase (JAK) 1 and JAK3 and trigger the signal transducer and activator of transcription (STAT)-1, -3 and -5 , insulin receptor signaling (IRS) and RAS-mitogen-activated protein kinase (MAPK) pathways. In addition, IL-9 is not expressed by Th 2 and 9 cells in the absence of STAT6 expression. Dysregulated IL-9 response also leads to autonomous cell growth and the malignant transformation of lymphoid cells associated with constitutive activation of the JAK/STAT pathway in vitro. The current review summarizes the characterization of the biological activities of IL-9, highlights the clearly defined roles of the cytokine, and outlines questions with regard to the functions of IL-9 that require further exploration and their downstream signaling proteins, STATs.

\section{IL-9 production and function}

IL-9-secreting cells. Initially, IL-9 was described as a $\mathrm{T}$ cell-derived cytokine with pleiotropic activities on various cell types. IL-9 is mainly expressed by activated CD4 ${ }^{+} \mathrm{T}$ cells, including Th2, Th9, Th17 and Treg cells (3). As compared with plate-bound anti-CD3 mAb/soluble anti-CD28 mAb plus transforming growth factor (TGF)- $\beta$ stimulation, IL-4 and TGF- $\beta$ stimulate memory CD4(+), CD25(-) and CD45RO(+) $\mathrm{T}$ cell expression, inducing higher levels of IL-9 expression, but reducing forkhead box (Fox) p3 protein expression. IL-4 and TGF- $\beta$ inhibit the expression of Foxp 3 that induces Treg generation and promotes an IL-9-secreting phenotype, which is dependent on STAT6. Similarly, Gata3 is required for the generation of IL-9-secreting cells, suggesting that the IL-9-secreting population has shared factors in their development. Human T cells also acquire IL-9-secreting potential when cultured with TGF- $\beta$ and IL-4. IL-9 production was first associated with the Th2 phenotype (4). However, it was unclear whether specialized cells were responsible for IL-9 production and secretion, as was being established at the time 
for other cytokines, including IL-4 and interferon (IFN) $\gamma$, in Th2 and Th1 cells, respectively.

Studies have shown that two transcription factors are required for IL-9-secreting cells and have been reported to bind directly to the $I l 9$ gene. PU.1 is an ETS-family transcription factor. PU.1-deficient T cells exhibit diminished IL-9 production and ectopic expression of PU.1 increases IL-9 production from Th2 or Th9 cultures (5-7). PU.1 binds directly to the $I l 9$ gene and histone modifications associated with the Th9 phenotype are dependent upon PU.1. PU.1-specific small interfering RNA results in impaired IL-9 production by human T cells; therefore, PU.1 is also important for IL-9 production in human T cells. Notably, PU.1 is expressed in greater amounts in cells cultured under Th9 conditions compared with Th 2 cells, which suggests that PU.1 is a critical factor in diverting Th2 cells into an IL-9-secreting lineage (7). In a previous follow-up study, in the absence of PU.1, a decreased association between Gcn5 and p300/CREB-binding protein (CBP) associated factor and inhibition of the expression of Gcn5 was found to result in reduced IL-9 production, which suggested that Gen5 may be important in PU.1-dependent IL-9 production. Similar to PU.1, IFN-regulatory factor 4 (IRF4) was also shown to be required for Th9 generation and, possibly in concert with PU.1, since IRF4 was originally identified as a PU.1-interacting protein, IRF4 binds to the $I l 9$ gene directly. In addition, IRF4 expression has been associated with human and mouse Th9 differentiation and is induced by cytokines that promote IL-9 production, including IL-4, IL-2 and TGF- $\beta$ (8). IRF4 is important in the cytokine-secreting potential of several Th subsets as IRF4 is also required for Th2 and Th17 development (9-11).

Mast cells (MCs) also produce IL-9 in response to lipopolysaccharides and IL-1, which are associated with the presence of nuclear factor $\kappa \mathrm{B}(\mathrm{NF}-\kappa \mathrm{B})$ binding sites in the $I l 9$ promoter that mediate gene activation (12-14). Gatal in MCs promotes IL-9 production and $I l 9$ promoter activation is dependent upon p38 MAPK (15). MCs and T cells, as well as the scenarios in which each cell may contribute to IL-9 production in vivo, have not previously been determined. In addition, IL-9 induces MC production of TGF- $\beta$, which exhibits proinflammatory downstream effects (Fig. 1).

IL-9R signaling and expression. The functions of IL-9 are mediated by the IL-9R, which is a member of the hematopoietin receptor superfamily (16). The IL-9R is shared with the IL-2, -4, -7, -15 and -21 receptors, including the ligand-specific $\alpha$ chain and the common $\gamma$ chain. The mouse receptor contains 468 amino acids, but the human IL-9R gene contains 11 exons and encodes a 522-amino acid protein. On the basis of the presence of the WSXWS motif in the extracellular domain and Box1 and Box 2 motifs in the intracellular domain, the IL-9R $\alpha$ is a member of the hematopoietin superfamily. The Box1 intracellular domain is critical for IL-9-induced cell growth, activation of STAT3 and induced gene expression, which is between amino acids 338 and 422, including a YLPQ motif. Although IL-9R $\alpha$ expression is not induced by Tax, expression of IL-9 is activated by Tax via an NF- $\kappa$ B motif in its proximal promoter.

The IL-9R and common $\gamma$ chains associated with JAK1 and JAK3, trigger STATs-1, -3 and -5 . In addition, they activate the IRS and RAS-MAPK pathways, although, the physiological requirement for these pathways in primary cells has not previously been well documented (17). A single tyrosine residue (Tyr407) in the IL-9R $\alpha$ is phosphorylated following ligand binding to the receptor and activation of associated JAK1. The mutation of this residue demonstrates that it is required for IL-9-dependent responses.

As predicted from its initial identification as a T-cell growth factor, IL-9R is expressed in T-cell lines and effector $\mathrm{T}$ cells, but not in naïve $\mathrm{T}$ cells $(18,19)$. Among the Th-cell subsets, IL-9R exhibits its highest expression in Th2 and Th17 cells (13). IL-9R is found on MCs and polymorphonuclear leukocytes $(20,21)$. Additionally, IL-9R is expressed in non-hematopoietic cells. Since $\gamma c$ is unlikely to be expressed in these cells, the exact composition of the receptor in non-hematopoietic cells has not been clearly defined.

Effect of IL-9 on B cells. Traditionally, IL-9 is described as a T-cell-derived cytokine with pleiotropic activities on various cell types. More recently, IL-9 expression has been linked to B cells $(22,23)$. IL-9 not only exerts effects on B-cell development but also on function. Transgenic expression of IL-9 recovers the $\mathrm{B} 1$ cell numbers, but not natural IgM production,

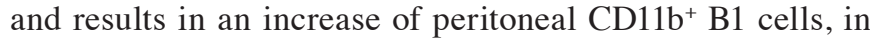
xid mice (24,25). IL-9 enhances IL-4-mediated IgE and IgG production from human B cells, but has no effect on IgM production $(26,27)$. IL-9 exerts similar effects on germinal center B cells and IL-9R $\alpha$ expression is greater on such B cells than on other types of B cells (28).

IL-9-dependent regulation of hematological malignancies. IL-9 is a T-cell-derived lymphokine that induces the proliferation of various lymphoid and hemopoietic cells (29). The HTLV-I protein, Tax, is important in the early stages of adult T-cell leukemia/lymphoma (ATL) based on altered gene expression, including that of cytokines and their receptors. Supporting a role for IL-9/IL-9R $\alpha$ in ATL, a previous study showed that a neutralizing monoclonal antibody inhibited the ex vivo spontaneous proliferation of primary ATL cells obtained from several patients, directed toward IL-9R $\alpha$. Freshly isolated peripheral blood mononuclear cells from these patients revealed high expression levels of IL-9R $\alpha$ on their CD14-expressing monocytes by fluorescence-activated cell sorting analysis. Furthermore, purified T cells or monocytes did not independently proliferate from these patients ex vivo, whereas mixtures of these cell types manifested significant proliferation in a contact-dependent manner. Overall, these results suggested that primary ATL cells support the action of IL-9R $\alpha /$ CD14-expressing monocytes via IL-9, which subsequently supports the ex vivo spontaneous proliferation of malignant $\mathrm{T}$ cells. In conclusion, these results supported the theory that IL-9 and its receptor are involved in ATL through a paracrine mechanism $(17,30)$.

Previous studies analyzing the culture supernatants of peripheral blood mononucleated cells (PBMCs) from the early phases of ATL patients with spontaneous proliferation using the cytokine-dependent indicator cell line, NK-92, have revealed that the majority of six-day culture supernatants of PBMCs from ATL patients contain high amounts of IL-9 (31). The presence of IL-9 in the culture supernatants was also confirmed by ELISA analysis. Furthermore, in 


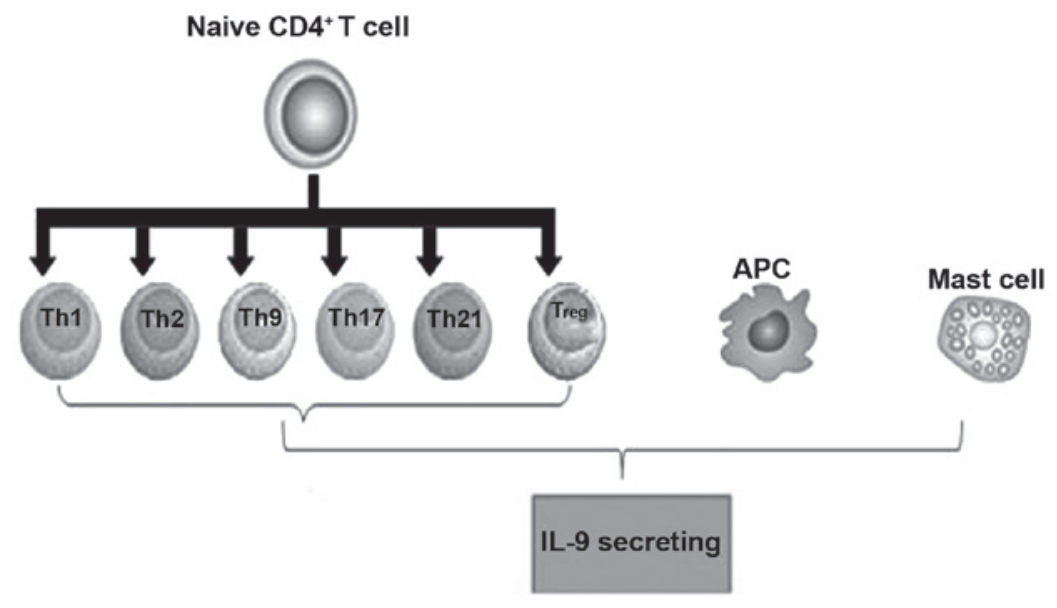

Figure 1. IL-9-secreting cells. IL-9, interleukin-9; Th, T-helper; Treg, regulatory T; APC, antigen presenting cell.

certain ATL patients within this group, the spontaneous proliferation was blocked by a monoclonal antibody against IL-9R $\alpha$. This suggested that the IL-9/IL-9R system may be involved in the expansion of the HTLV-I-infected CD4 ${ }^{+}$ $\mathrm{T}$ cells of specific patients in the early stages of ATL (32). IL-9 is a Th2 cytokine and IL-9 is produced in $>80 \%$ of smoldering/chronic ATL ex vivo PBMC cultures, which has previously shown that HTLV-1 Tax transactivates IL-9 expression in HTLV-1-infected T-cell lines (30). Prevention of histone acetylation by the histone acetyltransferase inhibitor, curcumin, diminished PU.1 expression following IL-9-inducing stimulation. Autocrine/paracrine cytokine stimulation of leukemic cell proliferation has been identified in patients with smoldering/chronic ATL that may be targeted for treatment. The etiologic agent of ATL is HTLV-I.

Anaplastic lymphoma kinase (ALK) has been implicated in the growth of neoplastic cells in malignant lymphomas. Although IL-9 has been implicated in the growth of normal MCs, little is known concerning pro-oncogenic molecules and conditions triggering differentiation and growth of MC to lead to the histopathological image of overt mastocytosis. Certain previous studies have described that transplantation of nucleophosmin (NPM)-ALK-transplanted mouse bone marrow progenitors into lethally irradiated IL-9 transgenic mice not only results in lymphoma formation, but also in the development of a neoplastic disease exhibiting histopathological features of systemic mastocytosis. These include multifocal dense MC infiltrates, occasionally with devastating growth in visceral organs. Transplantation of $N P M-A L K$-transduced progenitors into normal mice or maintenance of IL-9 transgenic mice without NPM-ALK both resulted in MC hyperplasia, but not in mastocytosis. Neoplastic MCs in mice are not only exhibited in IL-9, but also the IL-9R, as was found in human neoplastic MCs. Overall, the data show that neoplastic MCs express IL-9Rs. In addition, IL-9 and NPM-ALK upregulate MC production in vivo and the two 'hits' act in concert to induce a mastocytosis-like disease in mice (33). These results may have pathogenetic and clinical implications, and are consistent with the observation that neoplastic MCs in advanced systemic mastocytosis markedly express NPM and multiple 'lymphoid' antigens, including CD25 and CD30.

\section{Characteristics and expression of STATs}

STAT3 target genes. STAT3 is a cytoplasmic transcription factor and a member of the STAT family. Aberrant STAT3 activation is considered a molecular abnormality that supports the tumor phenotype and is detected with high frequency in hematological malignancies. STAT3 is involved in embryonic stem (ES) cell self-renewal (stemness) of certain mammalian cell types and species. Generally, STAT3-mediated transcription directs cells into cell survival and cell cycle progression. STAT3 is involved in cellular transformation and tumorigenesis (34). However, the molecular mechanisms leading to the aberrant STAT3 activation and STAT3-mediated transformation and tumorigenesis remain unclearly defined.

STAT3 proteins are also activated via cytoplasmic kinases of the Src kinase family and via the tyrosine kinase activity of various growth factor receptors. Cytokines activate STAT3 proteins differentially, utilizing the gp130 receptor component, including ciliary neurotrophic factor, oncostatin $\mathrm{M}$, leukemia-inhibitory factor (LIF) and IL-6. STAT3 proteins are also activated by growth hormones, including thrombopoietin, granulocyte colony-stimulating factor, granulocyte-macrophage colony-stimulating factor, basic fibroblast growth factor and a number of ILs (35). The results of previous proteomic studies have uncovered an interdependence of STAT3 signaling and members of the Rho family of small GTPases, including Rac1, Cdc42 and RhoA. Specifically, Rac1, acting in complex with the male germ cell, RacGAP, promotes tyrosine phosphorylation of STAT3 by the IL6-receptor family/JAK complex, as well as its translocation to the nucleus. Evidence has further demonstrated that the mutational activation of Rac1 and Cdc42 results in STAT3 activation, which occurs, in part, through the upregulation of the IL6 family of cytokines that, in turn, stimulate STAT3 through JAKs. Notably, previous studies have also shown that the engagement of cadherins and cell-to-cell adhesion molecules, specifically, induce a marked increase in Rac1 and Cdc42 protein levels and activity, which, in turn, results in STAT3 activation (36).

STAT3 is tightly integrated into the gene regulatory mechanism of pluripotency. Previously, Kidder et al (37) applied chromatin immunoprecipitation (ChIP) sequencing technology to use promoter arrays of mouse ES cells (mESCs) that cover 
28,000 promoter regions in the genome. The authors found 948 putative target genes for STAT3, with 29 of these genes co-occupied by Oct4 and Nanog. In addition, Chen et al (38) used the ChIP-chip approach to map the binding sites for STAT3 in mESCs. The authors identified 2,546 genomic sites where STAT3 was bound and approximately one-third (718) of these loci were bound by Oct4, Sox 2 and Nanog.

The target gene list contains transcriptionally active and inactive genes. A number of pluripotency genes, such as Oct4 and Nanog, exist among the STAT3-binding sites (39). The inactive genes include developmentally regulated tissue-specific genes, including Gata3 (ectoderm-specific), Foxa2, Gata4 (the two endoderms), $T$ (brachyury), LIM homeobox protein 1 (mesoderm) and Eomes (trophectoderm). Although the present review did not identify whether STAT3 suppresses these genes, it is possible that STAT3 mediates the suppression of differentiation genes and that this mechanism may be one method in which LIF prevents the differentiation of mESCs into endoderm and mesoderm lineages (40). In a previous study, although the authors did not report whether any of these 113 suppressed genes included the aforementioned developmentally regulated genes, it was found that STAT3 was bound to 113 genes that were also bound by subunits of the polycomb repressive complex 2, such as Suz12 and Eed (37). In general, STAT proteins function as transcriptional activators, but STAT1 is known to suppress the transcription of matrix metalloproteinases and cell-cycle genes (c-Myc, cyclin D and cyclin A) (41). Therefore, STAT3 may also function as a suppressor. Along an associated line of inquiry, Bourillot et al (42) knocked down 22 STAT3 target genes and found that 16 induced activation of endodermal genes and one activated mesodermal genes. These observations are consistent with the theory that STAT3 contributes to the prevention of mESC differentiation by suppressing lineage-specific genes.

STAT3-binding proteins and gene activation. An additional method to understanding how STAT3 regulates gene expression is to identify proteins that interact with STAT3. The interacting proteins include the transcription factors, $\mathrm{NF}-\kappa \mathrm{B}$ (43) and c-Jun (44), the coactivators, nuclear receptor coactivator 1/SRC1a (45) and Ctr9 (46), and the chromatin remodeling adenylpyrophosphatase (ATPase) brahma-related gene 1 (Brg1) (47,48), p300/CBP. These interactions have been previously studied outside the field of stem cell biology, but similar interactions are likely to occur in mESCs since specific interacting partners are colocalized with STAT3 on the mESC genome. The transactivation domain of STAT3 at the C-terminus interacts with a number of chromatin proteins, including p300/CBP and is colocalized with STAT3 on a number of pluripotency genes (38).

Of particular interest is Brg1, a catalytic subunit of the switch/sucrose non-fermentable ATPase complex that is associated with pluripotency at several levels. Brg1 is involved in chromatin relaxation (99); however, the role of Brg1 in mESCs is not limited to chromatin relaxation. Previously, it was demonstrated that the ESC-specific chromatin remodeling esBAF complex contains Brg1 $(50,51)$. esBAF is colocalized with STAT3 throughout the genome, including in pluripotency genes. Although esBAF binds to a number of pluripotency genes in ESCs, it maintains pluripotency primarily by suppressing differentiation-specific genes (49). Additionally, Brg1 facilitates the binding of Oct 4 to its target genes and increases the efficiency of the dedifferentiation of fibroblasts to a pluripotent state (52). Although little is known concerning the details of the interaction between Brg1 and STAT3 during LIF stimulation, recruitment of Brg1 occurs prior to or following STAT3 binding to its target genes, depending on the particular IL-6 target genes. For specific IL-6 target genes, Brg1 is constitutively bound and its presence is necessary for the recruitment of STAT3 (47). For other IL-6 target genes, STAT3 binds first to its DNA and then Brg1 is recruited depending on the presence of STAT3 (48).

Ctr9 is a subunit of the Pafl complex. The STAT3-Ctr9 interaction is highly significant for pluripotency of mESCs since Ctr9 indirectly induces multiple histone modifications, including trimethylation of Lys4 and Lys36, dimethylation of Lys79 on histone $\mathrm{H} 3$ and ubiquitination of histone $\mathrm{H} 2 \mathrm{~B}$, all of which are important for gene activation (53). Consistent with this, the level of trimethylation of Lys4 on histone $\mathrm{H} 3$ on specific IL-6-inducible genes is dependent on the presence of Ctr9 (46). It appears that the interaction between STAT3 and Ctr9 is important for the recruitment of STAT3 to its target genes in this case. Although it is not known whether LIF also induces the interaction between STAT3 and Ctr9 in mESCs, confirmation is likely to provide the first molecular link between LIF and epigenetic modifications in ESCs. The Paf1 complex also binds to Oct4 in mESCs $(54,55)$, but it is unknown whether STAT3 is relevant to this binding.

STAT6 target genes. STAT6 is a transcription factor and mainly responsible for their own transcriptional effects. It is primarily activated by IL-4 and IL-13 and its C-terminal Src homology 2 (SH2) domain is a specific phosphorylated receptor site. STAT6 is phosphorylated on Tyr641 and is subsequently activated. The STAT6 protein then dimerizes and translocates to the nucleus where it binds to STAT regulatory elements and regulates transcription in association with other transcription factors in its activated form (56). Previously, STAT6 has been reported to be constitutively activated in HL-derived cell lines (57).

Previously performed high-throughput sequencing of chromatin immunoprecipitated DNA has identified genes bound by STAT6. In addition, a previous study compared genes bound by STAT6 in wild-type and STAT6 ${ }^{-1-}$ Th2 cells and these results were compared with epigenetic modifications across the genome (58). In the current study, H3K4me3 was colocalized with $60 \%$ of the binding sites for STAT6. Various permissive epigenetic marks were coincided with specific STAT6-bound regions and IL-4, Gata3, IL-24, phospholipase $\mathrm{C} \delta 1$ and homeodomain interacting protein kinase 2 were included in the corresponding genes (58). In an additional study, human Th2 cells were used and compared with the STAT6 binding to genes between cells where the expression of STAT6 was knocked down by RNA interference and cells with normal STAT6 expression (59). In the present study, a kinetic analysis was performed and the identity of STAT6-dependent genes during the $\mathrm{Th} 2$ polarization process was determined. It was found that $80 \%$ of IL-4 regulated genes were dependent on STAT6 at the 48-h time point. Specific genes regulated 
by STAT6 included Gata3, CRTH2, IL-24, lymphotoxin $\beta$, suppressor of cytokine signaling (SOCS) 1. A resource which may be used for future studies to define further roles of STAT6 in T and B cells is provided with high-throughput screening for STAT6-regulated genes. Emerging evidence shows that STAT6 functions in other immune cells, as well as other non-immune cells. STAT6 is likely to be significant in determining the nature of genes that are regulated by STAT6 in these tissues.

STAT6-binding proteins and gene activation. STAT6 functions may be analyzed using mice with disrupted Stat6 alleles. A previous mouse study demonstrated that STAT6 is critical for a number of responses in T cells, including the development of Th2 cells and IL-4-stimulated proliferative responses. The expression of Th2 cytokines, including IL-4, -5 and -13, was diminished in Stat $^{-1-}$ mice (60). The expression of Gata3, the master regulator of Th2 differentiation, may be regulated by STAT6 (61). STAT6 is also required for the development of IL-9-secreting T cells (62-64). The mechanisms by which STAT6 regulates T-cell proliferation include decreasing the expression of $\mathrm{p} 27^{\mathrm{Kipl}}$, a known cyclin-dependent kinase inhibitor, which may be at the transcriptional and post-translational levels $(65,66)$. STAT6 is required for cytotoxic T2-cell differentiation, as the production of IL-4 and IL-5 is completely lost with STAT6 deficiency in CD8 cells (67). Overall, STAT6 is required for IL-4-stimulated T-cell functions.

In B cells, STAT6 promotes immunoglobulin class switching to $\operatorname{IgE}$ and $\mathrm{IgG} 1$, as well as promoting the expression of specific cell surface molecules responsible for antigen presentation by B cells (68). In a previous study, the levels of $\operatorname{IgE}$ were evidently reduced in STAT6-deficient mice when the mice were sensitized with antigen or infected with $N$. brasiliensis (61). No differences were identified in immunoglobulin class switching to IgG1 when STAT6 ${ }^{-/}$and control mice were immunized with IgD, but the levels of IgG1 were reduced in STAT6-deficient mice, an infection model with $N$. brasiliensis or S. mansoni (69). The expression of several cell surface molecules responsible for antigen presentation by B cells is induced by IL-4, including MHC II, CD80 and CD86. Previous studies using STAT6 $^{--}$B cells and mice expressing a constitutive form of STAT6 showed that the IL-4-mediated induction of these molecules is dependent on STAT6 $(60,68)$. The expression of other cell surface molecules, such as CD23 and IL-4R- $\alpha$, are also induced by STAT6 (68). CD23 is the low-affinity $\mathrm{Fc}$ receptor for $\operatorname{IgE}$ and is also a B-cell differentiation marker. The induction of IL-4R- $\alpha$ by STAT6 indicates that STAT6 promotes an autocrine-positive feedback loop for IL-4-dependent signaling. In B cells, STAT6 is required for IL-4-stimulated proliferation, similar to the previously described role of $\mathrm{T}$ cells (61). In addition, apoptosis is prevented in B cells by IL-4 in a STAT6-dependent manner (70).

STAT6 also functions in macrophages and dendritic cells, in addition to a requirement in T and B cells. STAT6 mediates IL-13-induced expression of genes, including MHC class II, and promotes IL-4-induced differentiation of alternatively activated macrophages (AAM) in macrophages $(71,72)$. STAT6 activity in AAMs is associated with the suppression of T-cell proliferation (73). Currently, one previous study has shown that STAT6 facilitates the transcription mediated by the peroxisome proliferator-activated- $\gamma$ receptor in macrophages and dendritic cells (74). STAT6 is capable of downregulating the production of IL-10 and promoting the production of IL-12 to promote a Th1 response in dendritic cells (75). Thus, STAT6 is vital in regulating the balance of inflammatory and allergic immune responses.

STAT pathway in hematological malignancies. STAT proteins are activated by a wide range of cytokines and growth factors, typically via cytokines through the JAK family of tyrosine kinases (76).

Aprevious study revealed a close cross-talk correlation between STAT3 and phosphoinositide 3-kinase (PI3K) (77). STAT3 in PI3K-transformed murine cells is phosphorylated on Y705 and activated in a PI3K-dependent manner. Dominant-negative STAT3 interferes with PI3K-induced oncogenic transformation. In PI3K-transformed murine cells, phosphorylation of STAT3 is mediated by the TEC kinase, BMX. STAT3 is important in PI3K-driven oncogenic transformation and marks BMX as a promising therapeutic target that may enhance the efficacy of PI3K inhibitors. The PI3K-mammalian target of rapamycin and STAT3 signaling pathways represent two different regulatory networks. The functional link between these pathways is significant for the understanding of the PI3K- and STAT3-driven oncogenic mechanisms and identifies the TEC kinase, BMX, as a new cancer target.

STAT3 mutations unify the pathogenesis of chronic lymphoproliferative disorders of natural killer (NK) cells and T-cell large granular lymphocyte leukemia. STAT3 gene mutations are present in T and NK cell diseases. Mutations have been found in exons 21 and 20, encoding the SH2 domain. Constitutive STAT3, Tyr705 and Ser727 phosphorylation caused by the autocrine secretion of IL- 6 exist in acute myeloid leukemia cells, murine plasmacytomas and hybridomas. In addition, STAT3-mediated constitutive expression of SOCS-3 is present in cutaneous T-cell lymphoma (78).

STAT3 is crucial in promoting the progression of hematological malignancies, including chronic lymphocytic leukemia (CLL). In CLL, STAT3 is constitutively phosphorylated on serine 727, regardless of blood count, disease stage or treatment status and not on the tyrosine 705 residue; however, the biological significance of serine-phosphorylated STAT3 (pSTAT3) is not known. A previous study demonstrated that constitutive serine pSTAT3 translocates to the nucleus by the karyopherin- $\beta$ nucleocytoplasmic system and binds to DNA. Dephosphorylation of inducible tyrosine pSTAT3 did not affect STAT3-DNA binding. Furthermore, infection of CLL cells with lentiviral STAT3-small hairpin RNA (shRNA) reduced the expression of several STAT3-regulated survival and proliferation genes and induced apoptosis. Overall, the results suggested that constitutive phosphorylation of STAT3 on the serine 727 residue is a hallmark of CLL and that STAT3 may be considered a therapeutic target in this disease (79).

Targeting sphingosine-1-phosphate (S1P)/sphingosine-1-phosphate receptor 1 (S1PR1) using a clinically relevant and available drug or other approaches is potentially an effective, new therapeutic modality for treating the activated B cell-like subtype of diffuse large 


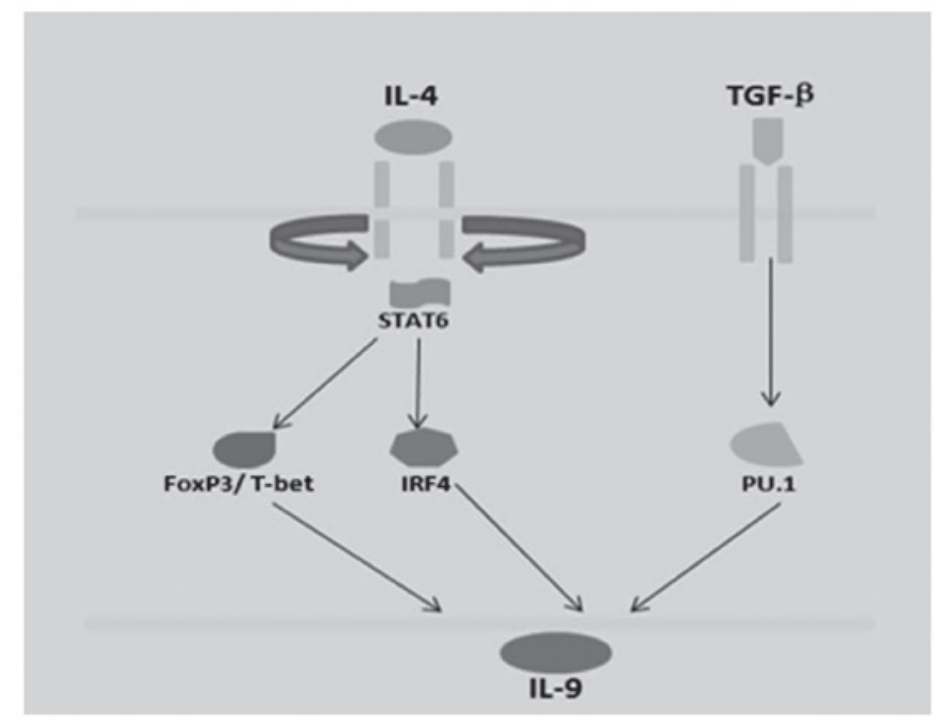

Figure 2. Association between IL-9 and STAT6. IL-9, interleukin-9; STAT6, signal transducer and activator of transcription 6; TGF, transforming growth factor; IRF4, interferon regulatory factor 4; FoxP3, forkhead box P3.

B-cell lymphoma, a subset of lymphoma that is less responsive to current available therapies. Studies have shown that using S1PR1 shRNA, a G protein-coupled receptor for S1P or FTY720, an antagonist of S1P that is used clinically for other indications, inhibits S1PR1 expression and downregulates STAT3 activity, causing growth inhibition of the B-cell lymphoma tumor cells in vitro and in vivo (80).

Recurrent mutations of the STAT6 DNA binding domain strongly support the involvement of STAT6 in the pathogenesis of this aggressive B-cell lymphoma (81). The STAT6 signaling pathway, activated by the cytokines IL-4 and IL-13, induces expression of the Epstein-Barr virus (EBV)-encoded protein LMP-1 in absence of the EBV nuclear antigen 2; implicating the type II EBV latent gene expression in HL (82).

\section{Role of STAT3 and STAT6 in IL-9 production and its immune function}

STAT3 is a central cytoplasmic transcription factor that is activated by the phosphorylation of a conserved tyrosine residue in response to oncogenic proteins and extracellular signals, such as cytokines and growth factors (83). STAT3 regulates a number of genes that are critical to tumor cell survival and proliferation, angiogenesis, invasion, metastasis and immune evasion $(84,85)$. Previous extensive studies have demonstrated that inappropriate activation of STAT3 occurs at a high frequency in a wide variety of human cancers, including leukemia and lymphoma (86-89). Co-expression of the IL-9Ra chain promotes JAK1 mutant phosphorylation and STATs activation, including STAT1, STAT3 and STAT5.

In addition, Th2 and Th9 cells are described as IL-9-secreting cells, and culture with TGF- $\beta 1$ may increase IL-9 production. Th9 cells are derived in culture with a combination of TGF- $\beta 1$ and IL- 4 . In addition, Th9 cells are associated with Th2 cells in that they require STAT6 and Gata3 for development, but exhibit reduced expression of Th2 cytokines. STAT6 is required for the expression of Gata3 in Th9 cells (90). Ectopic expression of Gata3 reduced IL-9 production in wild-type cells but did not induce IL-9 production when transduced into STAT6 ${ }^{-1}$ Th9 cultures, suggesting that it is not directly regulating the $I l 9$ gene. It is possible that Gata3 is an intermediate in the STAT6-dependent reduction. IL-9 is not expressed by Th2 and Th9 cells in the absence of STAT6 expression (Fig. 2).

\section{Conclusions and future directions}

IL-9 is a multifunctional cytokine secreted by Th2 lymphocytes. The IL-9R and common $\gamma$ chains associated with JAK1 and JAK3 trigger STAT-1, -3 and -5. In addition, dysregulated IL-9 response leads to autonomous cell growth and malignant transformation of lymphoid cells associated with constitutive activation of the JAK/STAT pathway in vitro. The most recent example of a Th subset that requires multiple balanced signals to develop is Th9 cells that secrete IL-9. Th9 cells develop following exposure to TGF $\beta$ and IL-4, whereas TGF $\beta$ alone promotes the differentiation of Treg cells and IL-4 stimulates Th2 development (91). The integration of the two signals result in a Th subset that exhibits lower Foxp3 expression than Treg cultures and lower Th2 cytokine production than Th2 cells, but increased production of IL-9. However, it remains unclear how the integration of each signal results in the unique Th9 phenotype. In any case, the role of IL-9 and STATs has important implications for pathophysiology and treatment in hematological malignancies.

\section{Acknowledgements}

The present study was partly supported by grants from the Natural Science Foundations of Shandong Province, China (nos. Y2007C053 and ZR2009CM059), the Technology Development Projects of Shandong Province, China (nos. 2007GG10002008, 2008GG2NS02018 and 2010GSF10250), the Program for Outstanding Medical Academic Leader of Shandong Province, China and the Taishan Scholar Foundation of Shandong Province, China. 


\section{References}

1. Namkung JH, Lee JE, Kim E, et al: An association between IL-9 and IL-9 receptor gene polymorphisms and atopic dermatitis in a Korean population. J Dermatol Sci 62: 16-21, 2011.

2. Knoops L and Renauld JC: IL-9 and its receptor: from signal transduction to tumorigenesis. Growth Factors 22: 207-215, 2004.

3. Putheti P, Awasthi A, Popoola J, Gao W and Strom TB: Human CD4 memory T cells can become CD4+IL-9+ T cells. PLoS One 5: e8706, 2010.

4. van den Ham HJ, de Waal L, Andeweg AC and de Boer RJ: Identification of helper $\mathrm{T}$ cell master regulator candidates using the polar score method. J Immunol Methods 361: 98-109, 2010.

5. Chang HC, Han L, Jabeen R, Carotta S, Nutt SL and Kaplan MH: PU.1 regulates TCR expression by modulating GATA-3 activity. J Immunol 183: 4887-4894, 2009.

6. Chang HC, Zhang S, Thieu VT, Slee RB, Bruns HA, Laribee RN, Klemsz MJ and Kaplan MH: PU.1 expression delineates heterogeneity in primary Th2 cells. Immunity 22: 693-703, 2005.

7. Chang HC, Sehra S, Goswami R, Yao W, Yu Q, Stritesky GL, Jabeen R, McKinley C, Ahyi AN, Han L, et al: The transcription factor PU.1 is required for the development of IL-9-producing T cells and allergic inflammation. Nat Immunol 11: 527-534, 2010.

8. Staudt V, Bothur E, Klein M, Lingnau K, Reuter S, Grebe $\mathrm{N}$, Gerlitzki B, Hoffmann M, Ulges A, Taube C, et al: Interferon-regulatory factor 4 is essential for the developmental program of T helper 9 cells. Immunity 33: 192-202, 2010.

9. Ahyi AN, Chang HC, Dent AL, Nutt SL and Kaplan MH: IFN regulatory factor 4 regulates the expression of a subset of Th2 cytokines. J Immunol 183: 1598-1606, 2009.

10. Brustle A,Heink S, Huber M, Rosenplanter C, Stadelmann C, Yu P, Arpaia E, Mak TW, Kamradt T and Lohoff M: The development of inflammatory $\mathrm{T}(\mathrm{H})-17$ cells requires interferon-regulatory factor 4. Nat Immunol 8: 958-966, 2007.

11. Lohoff M, Mittrucker HW, Prechtl S, Bischof S, Sommer F, Kock S, Ferrick DA, Duncan GS, Gessner A and Mak TW: Dysregulated T helper cell differentiation in the absence of interferon regulatory factor 4. Proc Natl Acad Sci USA 99: $11808-11812,2002$.

12. Hültner L, Kölsch S, Stassen M, Kaspers U, Kremer JP, Mailhammer R, Moeller J, Broszeit H and Schmitt E: In activated mast cells, IL-1 up-regulates the production of several Th2-related cytokines including IL-9. J Immunol 164: 5556-5563, 2000.

13. Stassen M, Arnold M, Hültner L, Müller C, Neudörfl C, Reineke T and Schmitt E: Murine bone marrow-derived mast cells as potent producers of IL-9: costimulatory function of IL-10 and kit ligand in the presence of IL-1. J Immunol 164: 5549-5555, 2000.

14. Stassen M, Müller C, Arnold M, Hültner L, Klein-Hessling S, Neudörfl C, Reineke T, Serfling E and Schmitt E: IL-9 and IL-13 production by activated mast cells is strongly enhanced in the presence of lipopolysaccharide: NF-kappa B is decisively involved in the expression of IL-9. J Immunol 166: 4391-4398, 2001.

15. Stassen M, Klein M, Becker M, Bopp T, Neudörfl C, Richter C, Heib V, Klein-Hessling S, Serfling E, Schild H and Schmitt E: p38 MAP kinase drives the expression of mast cell-derived IL-9 via activation of the transcription factor GATA-1. Mol Immunol 44: 926-933, 2007

16. Osterfeld H, Ahrens R, Strait R, Finkelman FD, Renauld JC and Hogan SP: Differential roles for the IL-9/IL-9 receptor alphachain pathway in systemic and oral antigen-induced anaphylaxis. J Allergy Clin Immunol 125: 469-476, 2010.

17. Demoulin JB, Louahed J, Dumoutier L, Stevens M and Renauld JC: MAP kinase activation by interleukin-9 in lymphoid and mast cell lines. Oncogene 22: 1763-1770, 2003.

18. Cosmi L, Liotta F, Angeli R, Mazzinghi B, Santarlasci V, Manetti R, Lasagni L, Vanini V, Romagnani P, Maggi E, et al: Th2 cells are less susceptible than Th1 cells to the suppressive activity of CD25+ regulatory thymocytes because of their responsiveness to different cytokines. Blood 103: 3117-3121, 2004.

19. Druez C, Coulie P, Uyttenhove C and Van Snick J: Functional and biochemical characterization of mouse P40/IL-9 receptors. J Immunol 145: 2494-2499, 1990.

20. Abdelilah S, Latifa K, Esra N, Cameron L, Bouchaib L, Nicolaides N, Levitt R and Hamid Q: Functional expression of IL-9 receptor by human neutrophils from asthmatic donors: role in IL-8 release. J Immunol 166: 2768-2774, 2001.
21. Kearley J, Erjefalt JS, Andersson C, Benjamin E, Jones CP, Robichaud A, Pegorier S, Brewah Y, Burwell TJ, Bjermer L, et al: IL-9 governs allergen-induced mast cell numbers in the lung and chronic remodeling of the airways. Am J Respir Crit Care Med 183: 865-875, 2011.

22. Nowak EC, Weaver CT, Turner H, Begum-Haque S, Becher B, Schreiner B, Coyle AJ, Kasper LH and Noelle RJ: IL-9 as a mediator of Th17-driven inflammatory disease. J Exp Med 206: 1653-1660, 2009

23. Lu LF, Lind EF, Gondek DC, Bennett KA, Gleeson MW, Pino-Lagos K, Scott ZA, Coyle AJ, Reed JL, Van Snick J, et al: Mast cells are essential intermediaries in regulatory T-cell tolerance. Nature 442: 997-1002, 2006.

24. Knoops L, Louahed J and Renauld JC: IL-9-induced expansion of $\mathrm{B}-1 \mathrm{~b}$ cells restores numbers but not function of B-1 lymphocytes in xid mice. J Immunol 172: 6101-6106, 2004.

25. Vink A, Warnier G, Brombacher F and Renauld JC: Interleukin 9-induced in vivo expansion of the B-1 lymphocyte population. J Exp Med 189: 1413-1423, 1999.

26. Dugas B, Renauld JC, Pene J, Bonnefoy JY, Peti-Frère C, Braquet P, Bousquet J, Van Snick J and Mencia-Huerta JM: Interleukin-9 potentiates the interleukin-4-induced immunoglobulin ( $\mathrm{IgG}, \operatorname{IgM}$ and IgE) production by normal human B lymphocytes. Eur J Immunol 23: 1687-1692, 1993.

27. Petit-Frere C, Dugas B, Braquet P and Mencia-Huerta JM: Interleukin-9 potentiates the interleukin-4-induced IgE and IgG1 release from murine B lymphocytes. Immunology 79: 146-151, 1993.

28. Fawaz LM, Sharif-Askari E, Hajoui O, Soussi-Gounni A, Hamid Q and Mazer BD: Expression of IL-9 receptor alpha chain on human germinal center B cells modulates IgE secretion. J Allergy Clin Immunol 120: 1208-1215, 2007.

29. Renauld JC, Druez C, Kermouni A, Houssiau F, Uyttenhove C, Van Roost E and Van Snick J: Expression cloning of the murine and human interleukin 9 receptor cDNAs. Proc Natl Acad Sci USA 89: 5690-5694, 1992.

30. Chen J, Petrus M, Bryant BR, Phuc Nguyen V, Stamer M, Goldman CK, Bamford R, Morris JC, Janik JE and Waldmann TA: Induction of the IL-9 gene by HTLV-I Tax stimulates the spontaneous proliferation of primary adult T-cell leukemia cells by a paracrine mechanism. Blood 111: 5163-5172, 2008

31. Umezu-Goto M, Kajiyama Y, Kobayashi N, Kaminuma O, Suko M and Mori A: IL-9 production by peripheral blood mononuclear cells of atopic asthmatics. Int Arch Allergy Immunol 143 (Suppl 1): 76-79, 2007.

32. Chen J,Petrus M, Bryant BR, Nguyen VP, Goldman CK, Bamford R, Morris JC, Janik JE and Waldmann TA: Autocrine/paracrine cytokine stimulation of leukemic cell proliferation in smoldering and chronic adult T-cell leukemia. Blood 116: 5948-5956, 2010.

33. Merz H, Kaehler C, Hoefig KP, et al: Interleukin-9 (IL-9) and NPM-ALK each generate mast cell hyperplasia as single 'hit' and cooperate in producing a mastocytosis-like disease in mice. Oncotarget 1: 104-119, 2010.

34. Lin Q, Lai R, Chirieac LR, Li C, Thomazy VA, Grammatikakis I, Rassidakis GZ,Zhang W, Fujio Y, Kunisada K, et al: Constitutive activation of JAK3/STAT3 in colon carcinoma tumors and cell lines: inhibition of JAK3/STAT3 signaling induces apoptosis and cell cycle arrest of colon carcinoma cells. Am J Pathol 167: 969-980, 2005.

35. Dahéron L, Opitz SL, Zaehres H, Lensch MW, Andrews PW, Itskovitz-Eldor J and Daley GQ: LIF/STAT3 signaling fails to maintain self-renewal of human embryonic stem cells. Stem Cells 22: 770-778, 2004

36. Raptis L, Arulanandam R, Geletu M and Turkson J: The R(h) oads to Stat3: Stat3 activation by the Rho GTPases. Exp Cell Res 317: 1787-1795, 2011

37. Kidder BL, Yang J and Palmer S: STAT3 and c-Myc genome-wide promoter occupancy in embryonic stem cells. PLoS One 3: e3932, 2008.

38. Chen X, Xu H, Yuan P, Fang F, Huss M, Vega VB, Wong E, Orlov YL, Zhang W, Jiang J, et al: Integration of external signaling pathways with the core transcriptional network in embryonic stem cells. Cell 133: 1106-1117, 2008.

39. Kuznetsov VA, Singh O and Jenjaroenpun P: Statistics of protein-DNA binding and the total number of binding sites for a transcription factor in the mammalian genome. BMC Genomics 11 (Suppl 1): S12, 2010.

40. Ying QL, Nichols J, Chambers I and Smith A: BMP induction of Id proteins suppresses differentiation and sustains embryonic stem cell self-renewal in collaboration with STAT3. Cell 115: 281-292, 2003. 
41. Ramana CV, Chatterjee-Kishore M, Nguyen H and Stark GR: Complex roles of STAT1 in regulating gene expression. Oncogene 19: 2619-2627, 2000.

42. Bourillot PY, Aksoy I, Schreiber V, Wianny F, Schulz H, Hummel O, Hubner N and Savatier P: Novel STAT3 target genes exert distinct roles in the inhibition of mesoderm and endoderm differentiation in cooperation with Nanog. Stem Cells 27: $1760-1771,2009$.

43. Yu Z, Zhang W and Kone BC: Signal transducers and activators of transcription 3 (STAT3) inhibits transcription of the inducible nitric oxide synthase gene by interacting with nuclear factor $\mathrm{\kappa B}$. Biochem J 367: 97-105, 2002 .

44. Zhang X, Wrzeszczynska MH, Horvath CM and Darnell JE Jr: Interacting regions in STAT3 and c-Jun that participate in cooperative transcriptional activation. Mol Cell Biol 19: 7138-7146, 1999.

45. Giraud S, Bienvenu F, Avril S, Gascan H, Heery DM and Coqueret O: Functional interaction of STAT3 transcription factor with the coactivator NcoA/SRCla. J Biol Chem 277: 8004-8011, 2002.

46. Youn MY, Yoo HS, Kim MJ, Hwang SY, Choi Y, Desiderio SV and Yoo JY: hCTR9, a component of Paf1 complex, participates in the transcription of interleukin 6-responsive genes through regulation of STAT3-DNA interactions. J Biol Chem 282: 34727-34734, 2007.

47. Ni Z and Bremner R: Brahma-related gene 1-dependent STAT3 recruitment at IL-6-inducible genes. J Immunol 178: 345-351, 2007.

48. Giraud S, Hurlstone A, Avril S and Coqueret O: Implication of BRG1 and cdk9 in the STAT3-mediated activation of the p21waf1 gene. Oncogene 23: 7391-7398, 2004.

49. Ho L, Jothi R, Ronan JL, Cui K, Zhao K and Crabtree GR: An embryonic stem cell chromatin remodeling complex, esBAF, is an essential component of the core pluripotency transcriptional network. Proc Natl Acad Sci USA 106: 5187-5191, 2009.

50. Ho L, Ronan JL, Wu J, Staahl BT, Chen L, Kuo A, Lessard J, Nesvizhskii AI, Ranish J and Crabtree GR: An embryonic stem cell chromatin remodeling complex, esBAF, is essential for embryonic stem cell self-renewal and pluripotency. Proc Natl Acad Sci USA 106: 5181-5186, 2009.

51. Singhal N, Graumann J, Wu G, Araúzo-Bravo MJ, Han DW, Greber B, Gentile L, Mann M and Schöler HR: Chromatin-remodeling components of the BAF complex facilitate reprogramming. Cell 141: 943-955, 2010.

52. Guiter C, Dusanter-Fourt I, Copie-Bergman C, Boulland ML, Le Gouvello S, Gaulard P, Leroy K and Castellano F: Constitutive STAT6 activation in primary mediastinal large B-cell lymphoma. Blood 104: 543-549, 2004.

53. Gerber $\mathrm{M}$ and Shilatifard A: Transcriptional elongation by RNA polymerase II and histone methylation. J Biol Chem 278 : 26303-26306, 2003.

54. Ding L, Paszkowski-Rogacz M, Nitzsche A, Slabicki MM, Heninger AK, de Vries I, Kittler R, Junqueira M, Shevchenko A, Schulz H, et al: A genome-scale RNAi screen for Oct4 modulators defines a role of the Paf1 complex for embryonic stem cell identity. Cell Stem Cell 4: 403-415, 2009.

55. Ponnusamy MP, Deb S, Dey P, Chakraborty S, Rachagani S, Senapati S and Batra SK: RNA polymerase II associated factor 1/PD2 maintains self-renewal by its interaction with Oct3/4 in mouse embryonic stem cells. Stem Cells 27: 3001-3011, 2009.

56. Lessard JA and Crabtree GR: Chromatin regulatory mechanisms in pluripotency. Annu Rev Cell Dev Biol 6: 503-532, 2010.

57. Skinnider BF, Elia AJ, Gascoyne RD, Patterson B, Trumper L, Kapp U and Mak TW: Signal transducer and activator of transcription 6 is frequently activated in Hodgkin and Reed-Sternberg cells of Hodgkin lymphoma. Blood 99: 618-626, 2002.

58. Wei L, Vahedi G, Sun HW, Watford WT, Takatori H, Ramos HL, Takahashi H, Liang J, Gutierrez-Cruz G, Zang C, et al: Discrete roles of STAT4 and STAT6 transcription factors in tuning epigenetic modifications and transcription during $\mathrm{T}$ helper cell differentiation. Immunity 32: 840-851, 2010

59. Elo LL, Järvenpää $H$, Tuomela $S$, Raghav $S$, Ahlfors $H$, Laurila K, Gupta B, Lund RJ, Tahvanainen J, Hawkins RD, et al: Genome-wide profiling of interleukin-4 and STAT6 transcription factor regulation of human Th2 cell programming. Immunity 32 : $852-862,2010$

60. Takeda K, Tanaka T, Shi W, Matsumoto M, Minami M, Kashiwamura S, Nakanishi K, Yoshida N, Kishimoto T and Akira S: Essential role of STAT6 in IL-4 signalling. Nature 380: 627-630, 1996
61. Ansel KM, Djuretic I, Tanasa B and Rao A: Regulation of Th2 differentiation and I14 locus accessibility. Annu Rev Immunol 24: 607-656, 2006.

62. Dardalhon V, Awasthi A, Kwon H, Galileos G, Gao W, Sobel RA, Mitsdoerffer M, Strom TB, Elyaman W, Ho IC, Khoury S, Oukka M and Kuchroo VK: IL-4 inhibits TGF-beta-induced Foxp3+ T cells and, together with TGF-beta, generates IL-9+ IL-10+ Foxp3(-) effector T cells. Nat Immunol 9: 1347-1355, 2008.

63. Perumal NB and Kaplan MH: Regulating I19 transcription in T helper cells. Trends Immunol 32: 146-150, 2011.

64. Veldhoen M, Uyttenhove C, van Snick J, Helmby H, Westendorf A, Buer J, Martin B, Wilhelm and Stockinger B: Transforming growth factor-beta 'reprograms' the differentiation of T helper 2 cells and promotes an interleukin 9-producing subset. Nat Immunol 9: 1341-1346, 2008.

65. Kaplan MH, Daniel C, Schindler U and Grusby MJ: STAT proteins control lymphocyte proliferation by regulating p27Kip1 expression. Mol Cell Biol 18: 1996-2003, 1998.

66. Zhu J, Guo L, Min B, Watson CJ, Hu-Li J, Young HA, Tsichlis PN and Paul WE: Growth factor independent-1 induced by IL-4 regulates Th2 cell proliferation. Immunity 16: 733-744, 2002

67. Kaplan MH, Wurster AL, Smiley ST and Grusby MJ: STAT6-dependent and -independent pathways for IL-4 production. J Immunol 163: 6536-6540, 1999.

68. Bruns HA, Schindler U and Kaplan MH: Expression of a constitutively active STAT6 in vivo alters lymphocyte homeostasis with distinct effects in T and B cells. J Immunol 170: 3478-3487, 2003.

69. Kaplan MH, Whitfield JR, Boros DL and Grusby MJ: Th2 cells are required for the Schistosoma mansoni egg-induced granulomatous response. J Immunol 160: 1850-1856, 1998.

70. Wurster AL, Rodgers VL, White MF, Rothstein TL and Grusby MJ: Interleukin-4-mediated protection of primary B cells from apoptosis through STAT6-dependent up-regulation of Bcl-xL. J Biol Chem 277: 27169-27175, 2002.

71. Takeda K, Kamanaka M, Tanaka T, Kishimoto T and Akira S: Impaired IL-13-mediated functions of macrophages in STAT6-deficient mice. J Immunol 157: 3220-3222, 1996.

72. Martinez FO, Helming L and Gordon S: Alternative activation of macrophages: an immunologic functional perspective. Annu Rev Immunol 27: 451-483, 2009.

73. Huber S, Hoffmann R, Muskens F and Voehringer D: Alternatively activated macrophages inhibit T-cell proliferation by STAT6-dependent expression of PD-L2. Blood 116: 3311-3320, 2010

74. Szanto A, Balint BL, Nagy ZS, Barta E, Dezso B, Pap A, Szeles L, Poliska S, Oros M, Evans RM, et al: STAT6 transcription factor is a facilitator of the nuclear receptor PPARgamma-regulated gene expression in macrophages and dendritic cells. Immunity 33 : 699-712, 2010

75. Yao Y, Li W, Kaplan MH and Chang CH: Interleukin (IL)-4 inhibits IL-10 to promote IL-12 production by dendritic cells. J Exp Med 201: 1899-1903, 2005.

76. Furqan M, Mukhi N, Lee B and Liu D: Dysregulation of JAK-STAT pathway in hematological malignancies and JAK inhibitors for clinical application. Biomark Res 1: 5, 2013.

77. Bito T, Sumita N, Ashida M, Budiyanto A, Ueda M, Ichihashi M, Tokura $\mathrm{Y}$ and Nishigori C: Inhibition of epidermal growth factor receptor and PI3K/Akt signaling suppresses cell proliferation and survival through regulation of Stat 3 activation in human cutaneous squamous cell carcinoma. J Skin Cancer 2011: 874571, 2011.

78. Jeres A, Clemente MJ, Makishima H, Koskela H, Leblanc F, Peng Ng K, Olson T, Przychodzen B, Afable M, Gomez-Segui I, et al: STAT3 mutations unify the pathogenesis of chronic lymphoproliferative disorders of NK cells and T-cell large granular lymphocyte leukemia. Blood 120: 3048-3057, 2012.

79. Hazan-Halevy I, Harris D, Liu Z, Liu J, Li P, Chen X, Shanker S, Ferrajoli A, Keating MJ and Estrov Z : STAT3 is constitutively phosphorylated on serine 727 residues, binds DNA, and activates transcription in CLL cells. Blood 115: 2852-2863, 2010.

80. Ding BB, Yu JJ, Yu RY, Mendez LM, Shaknovich R, Zhang Y, Cattoretti $\mathrm{G}$ and $\mathrm{Ye} \mathrm{BH}$ : Constitutively activated STAT3 promotes cell proliferation and survival in the activated B-cell subtype of diffuse large B-cell lymphomas. Blood 111: 1515-1523, 2008

81. Ritz O, Guiter C, Castellano F, Dorsch K, Melzner J, Jais JP, Dubois G, Gaulard P, Moller P and Leroy K: Recurrent mutations of the STAT6 DNA binding domain in primary mediastinal B-cell lymphoma. Blood 114: 1236-1242, 2009. 
82. Kis LL, Gerasimcik N, Salamon D, Persson EK, Nagy N, Klein G, Severinson E and Klein E: STAT6 signaling pathway activated by the cytokines IL-4 and IL-13 induces expression of the Epstein-Barr virus-encoded protein LMP-1 in absence of EBNA-2: implications for the type II EBV latent gene expression in Hodgkin lymphoma. Blood 117: 165-174, 2011.

83. Bromberg JF, Wrzeszczynska MH, Devgan G, Zhao Y, Pestell RG, Albanese C and Darnell JE Jr: STAT3 as an oncogene. Cell 98: 295-303, 1999.

84. Bowman T, Garcia R, Turkson J and Jove R: STATs in oncogenesis. Oncogene 19: 2474-2488, 2000.

85. Haura EB, Turkson J and Jove R: Mechanisms of disease: Insights into the emerging role of signal transducers and activators of transcription in cancer. Nat Clin Pract Oncol 2: 315-324, 2005.

86. Frank DA, Mahajan S and Ritz J: B lymphocytes from patients with chronic lymphocytic leukemia contain signal transducer and activator of transcription (STAT) 1 and STAT 3 constitutively phosphorylated on serine residues. J Clin Invest 100: 3140-3148, 1997.

87. Mora LB, Buettner R, Seigne J, Diaz J, Ahmad N, Garcia R, Bowman T, Falcone R, Fairclough R, Cantor A, et al: Constitutive activation of STAT3 in human proSTATe tumors and cell lines: direct inhibition of STAT3 signaling induces apoptosis of proSTATe cancer cells. Cancer Res 62: 6659-6666, 2002.
88. Diaz N, Minton S, Cox C, Bowman T, Gritsko T, Garcia R, Eweis I, Wloch M, Livingston S, Seijo E, et al: Activation of STAT3 in primary tumors from high-risk breast cancer patients is associated with elevated levels of activated SRC and survivin expression. Clin Cancer Res 12: 20-28, 2006.

89. Scholz A, Heinze S, Detjen KM, Peters M, Welzel M, Hauff P, Schirner M, Wiedenmann B and Rosewicz S: Activated signal transducer and activator of transcription 3 (STAT3) supports the malignant phenotype of human pancreatic cancer. Gastroenterology 125: 891-905, 2003.

90. Eifan AO, Furukido K, Dumitru A, Jacobson MR, Schmidt-Weber C, Banfield G, Durham SR and Nouri-Aria KT: Reduced T-bet in addition to enhanced STAT6 and GATA3 expressing $\mathrm{T}$ cells contribute to human allergen-induced late responses. Clin Exp Allergy 42: 891-900,2012.

91. Hadjur S, Bruno L, Hertweck A, Cobb BS, Taylor B, Fisher AG and Merkenschlager M: IL4 blockade of inducible regulatory T cell differentiation: the role of Th2 cells, Gata3 and PU.1. Immunol Lett 122: 37-43, 2009. 